\title{
Postmortem evaluation of the use of diaphragmatic excursus in assessment of pulmonary emphysema in coal miners
}

\author{
H. I. MCKENZIE, K. G. OUTHRED, and M. GLICK \\ Joint Coal Board, New South Wales, Australia
}

\begin{abstract}
In a series of 89 subjects (all coal miners or ex-coal miners) a high order of correlation has been found between diaphragmatic excursus measured within five years of death and the necropsy assessment of emphysema in the lungs. In the absence of other common factors that reduce the range of movement of the diaphragm, measurements of diaphragmatic excursus provide a statistical prediction of the severity of emphysema. The individual variance, however, is such that this assessment should be used only as part of a range of clinicoradiological, physiological, and electrocardiographic indicators of emphysema severity.

Evidence is presented to show that the movement of the diaphragm is restricted in the predominantly emphysematous members of the series but approaches full normal range in the group with predominant chronic obstructive bronchitis.
\end{abstract}

The appearance of rarefied lung markings, a low flat diaphragm, a small low central heart shadow in a roomy thorax, and enlargement of the retrosternal clear space have been used as radiological diagnostic signs of emphysema for many years past. Simon $(1956,1964)$ also drew attention to the diminished range of diaphragm movement, which he stated was often less than 1 in $(2.5 \mathrm{~cm})$ in severe emphysema. He gave the normal range as 2 to 4 in (5 to $10 \mathrm{~cm}$ ). Reid (1960) and Reid and Millard (1964) have clarified the relationship of the radiographic and pathological features of emphysema. Milne and Bass (1969) found a good correlation between the specific dynamic pulmonary compliance and diaphragmatic excursus.

For the present paper the range of diaphragmatic movement in coal miners as recorded from measurement on fluoroscopic screening has been compared with the amount of emphysema found at necropsy in the lungs of the same subjects. From this a prediction formula for antemortem quantitation of emphysema has been derived. In a proportion of the subjects the availability of fullsize chest radiographs taken in full inspiration and full expiration enabled a parallel measurement to be made with the films overlain with first thoracic vertebrae exactly superimposed; these results were compared with those from fluoroscopy.

\section{DEFINITIONS AND METHODS}

There were 89 subjects (from a larger necropsy series) for whom both diaphragmatic excursus, measured within five years of death, together with other required data and necropsy assessment of emphysema were on record.

The subjects were either retired coal miners or employed coal miners exhibiting a wide range of radiological severity of coal dust pneumoconiosis and at necropsy a corresponding range pathologically. All had some degree of emphysema pathologically though in 12 subjects it was minimal. Fifty-three $(60 \%)$ were regarded at necropsy as having emphysema of varying degrees of the Gough 'dust focal' type. In many of these and also in the remaining 36, other types of emphysema - centrilobular, panacinar, and bullouswere also present. In many instances, chronic bronchitis, simple or obstructive, was adjudged to be present both clinically and pathologically, there being a considerable amount of overlap in the full series between the three components of pneumoconiotic nodules or masses, emphysema, and chronic bronchitis. The term emphysema as used in the text is a pathological condition of dilatation of lung air spaces with destruction of the alveolar walls.

The assessment of overall emphysema severity, regardless of type, was made on macroscopic examination of the external surfaces of both lungs and the surfaces of at least three cuts in the sagittal plane, with a representative paper-mounted whole-lung section prepared by the Gough-Wentworth technique, 
usually retained as a permanent record. The lungs had been perfused and fixed in inflation by the technique recommended by these authors. In addition, histological examination was made of representative sections from each lobe of each lung under low-power magnification $(\sim \times 5)$.

For macroscopic assessment each whole lung cut surface, taken in the sagittal plane, was divided into three approximately equal segments. Each segment was read as an approximate percentage of lung area involved as abnormal 'holes', and the results from the three or more cuts were averaged. These mean readings of the segments from each lung and then from both lungs were averaged to give an approximate percentage of total lung involvement, this being recorded in terms of $10 \%$ ranges. To obviate the possibility of inter-reader variation only one assessor undertook the quantitation of emphysema. The same observer made these assessments on two occasions (blind trial), the mean emphysema rating being $19 \cdot 1 \% \pm$ SD $14.9 \%$ and $18.3 \% \pm$ SD $13 \cdot 3 \%$ respectively (no significant difference, $\mathrm{P}<0 \cdot 20>0 \cdot 15$ ).

The presence or absence of pleural adhesions noted at the time of necropsy was classified separately for each lung according to the following grades: 0 , no adhesions; 1, sparse, mild or fresh adhesions; 2, moderate fibrotic adhesions or thickening; 3 , severe or widespread fibrotic adhesions or severe pleural thickening.

In the majority of the subjects histological measurements of lobar and segmental bronchi from each lobe of each lung had been carried out for derivation of the Reid index. An index of bronchitic airways obstruction-the mean cross-sectional area ratio of bronchial lumen to total bronchus internal to cartilage, measured in segmental and subsegmental bronchi cut transversely - was also determined. Our observations have shown that in normal subjects, those without obstructive disease, this ratio has a mean value of 0.51 with $90 \%$ range 0.44 or greater. It is considerably reduced in severe chronic bronchitis (assessed clinically from symptoms and signs recorded within five years of death). For this article the normal range of the Reid index has been accepted as $\mathbf{0 . 3 8}$ or less, with a mean value of $0 \cdot 29$.

The diaphragm excursus had been measured in the course of routine fluoroscopy carried out within five years of death.

At the time of screening the subjects were actively encouraged to achieve maximal inspiration and expiration and the dynamics of the diaphragm and thoracic cage movements were studied. Measurement of the static range of movement from held full inspiration to held full expiration, using a tape measure, was taken at the centre of each diaphragmatic dome. The results from both sides were averaged. The results included an excess (about 0.5 in $(1.25 \mathrm{~cm}$ ) in normal subjects) due to the geometrical lengthening inherent in the fluoroscopic procedure. This, however, does not affect the validity of the findings which are the subject of this paper.
The record of diaphragmatic excursus formed part of a detailed record of full routine clinical examination, symptom, smoking habit, and occupation questionnaire, chest radiological and fluoroscopic examination, and, in some instances, electrocardiography. The only respiratory function tests applied were the forced expired volume in one second $\left(\mathrm{FEV}_{1}\right)$ and vital capacity (VC) measurements. No results of body plethysmography were available.

The weight and height of all subjects, recorded at the time of fluoroscopy, were available, and from these data it was possible to assign to each subject a 'weight for age and height' grouping in terms of per cent over or under the expected weight by using the Australian Commonwealth Department of Health standard height-weight tables. In the absence of available statistics for coal miners it was assumed that these tables could be applied to them.

\section{FINDINGS}

The overall findings in the 89 subjects (Fig. 1) show a fair correlation $(r=-0.69$; SE 0.055$)$ between the recorded movement of the diaphragm and the percentage of emphysema assessed at necropsy. However, it was decided to examine the possibility that the presence of obesity, pleural adhesions or lung overinflation was influencing the results. In this particular series these were the only concurrent disorders found which seemed likely to restrict diaphragmatic movement.

In Fig. 1 the overweight $20 \%$ or greater group together with those having severe adhesions of one or both lungs or moderate adhesions of both lungs, and the one case of overinflation without emphysema included in the series (an asthmatic of 50 years' duration), have been identified. Their overall additive effect in restricting excursus is apparent. Lesser degrees of 'overweight' or pleural adhesions did not appear to be having any effect.

A regression formula excluding these 32 subjects was determined, and a high order of correlation is now achieved:

$$
\begin{aligned}
& \mathrm{E} \%=63-18.6 \text { d.e. (inches) } \pm 16.5 \\
& \text { ( } 95 \% \text { tolerance limits) } \\
& \mathrm{n}=57, \mathrm{r}=-0.87, \mathrm{SE}=0.033 \\
& \text { (d.e.=diaphramatic excursus) }
\end{aligned}
$$

Thus a theoretical prediction table can be formulated for use in the assessment as well as the diagnosis of emphysema (Table I).

The wide tolerance limits reduce the value of this prediction in the individual subject, and it should be used only as an adjunct to other clinical, radiological, electrocardiographic, and physiological criteria for overall assessment of emphysema. 


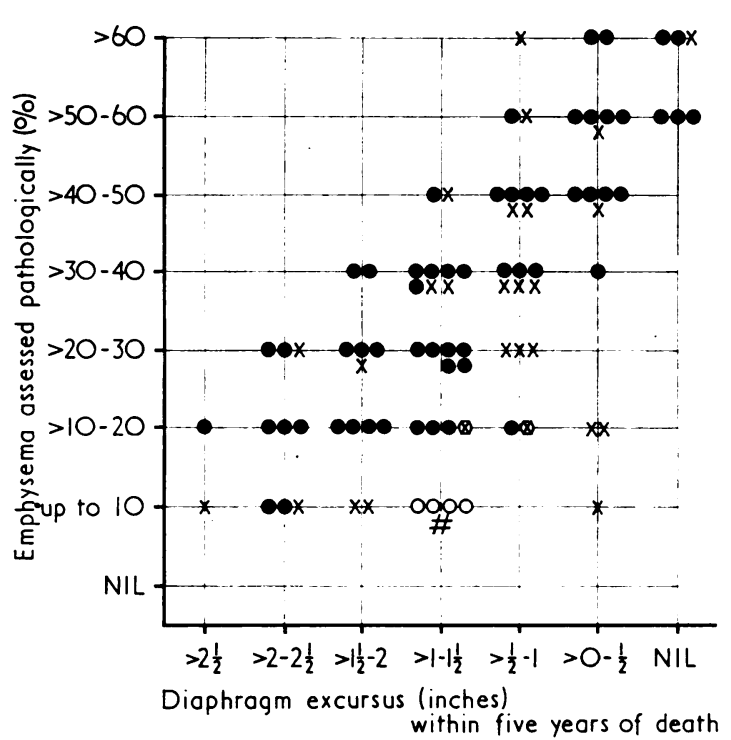

FIG. 1. Relation between extent of emphysema found postmortem and record range of diaphragmatic movement in 89 subjects. $\times$, subjects with severe adhesions in one or both lungs or with moderate adhesions of both lungs (as defined in text); $\bigcirc$, subjects overweight $>20 \%$ for age and height; \#, longstanding chronic asthmatic with chronic lung overinflation; , subjects with varying grades of emphysema without any of the above listed or other possible causes of diaphragmatic restriction.

\section{T A B L E I}

\begin{tabular}{ll|l}
\hline \multicolumn{2}{c|}{$\begin{array}{c}\text { Diaphragm Excursus } \\
\text { in }\end{array}$} & Predicted \% Emphysema \\
\hline Nil & & $55+$ \\
$0 \cdot 5$ & $1 \cdot 25$ & $45-55$ \\
$1 \cdot 0$ & $2 \cdot 50$ & $35-45$ \\
$1 \cdot 5$ & $3 \cdot 75$ & $25-35$ \\
$2 \cdot 0$ & $5 \cdot 00$ & $15-25$ \\
$2 \cdot 5$ & $6 \cdot 25$ & $<15$ \\
3.0 & 7.50 or more & Nil \\
\hline
\end{tabular}

FULL INSPIRATION-FULL EXPIRATION (FIFE) RADIOGRAPHS The use of 17 and 14 in FIFE radiographs to measure excursus of the diaphragm by the simple process of overlaying the films, taking due care to ensure that the first thoracic vertebrae are accurately superimposed, can give results which are as good as fluoroscopic screening. In this series there were 21 subjects who had diaphragm excursus documented by both fluoroscopic screening and FIFE films.

When the assessed emphysema ratings of subjects in this minor group were plotted against the FIFE measurements the correlation coefficient was -0.83 , SE 0.07 .
In our complete necropsy series of some 750 there were 34 subjects who had had fluoroscopic measurement of diaphragm excursus and who also had a FIFE measurement documented. An analysis was made of this group of 34 subjects. There was agreement between both measurements in five cases. Of the remainder, in $20(69 \%)$ the fluoroscopic diaphragm excursus range was the greater (average difference $0.60 \mathrm{in}$ ) as against nine cases in which the FIFE measurement was the greater (average difference $0.42 \mathrm{in}$ ).

Allowing for geometric difference in the two methods of measurement of the diaphragm excursus, then theoretically in the five cases in which there was agreement between the two measurements, the fluoroscopic screening measurement should have been the greater. This expectation would also apply to the nine cases in which the FIFE measurements were actually the greater. It is obvious, however, that whichever method is used to measure excursus it is imperative that the patient co-operate fully.

The authors prefer the fluoroscopic screening method since it enables the clinician to observe the diaphragm movement and thereby ensure that the patient is in fact co-operating fully, and also to study the dynamics of respiratory movement and the cardiac outline.

There appears to be no reason, however, why FIFE films should not be equally as accurate if the radiographer is conscientious and takes the time to explain to the patient the importance of completely full inspiration and expiration before the radiographs are taken. The above-mentioned correlation coefficient suggests that equally good results can be obtained with either method.

DIAPHRAGMATIC MOVEMENT AND BRONCHITIC AIRWAYS OBSTRUCTION The practical value of the demonstrated relationship between diaphragmatic excursus and per cent of emphysema at necropsy lies in the possible use of the former as an aid in the clinical analysis of obstructive lung disease. In an earlier paper, McKenzie, Glick and Outhred (1969) found a low order of correlation between recorded diaphragmatic excursus and two necropsy indices of severity of chronic bronchitis -the Reid index (gland/wall ratio) (Reid, 1960) and the mean wall/lumen ratio.

The two series of findings suggested that the restriction of diaphragm movement was directly related to the extent of emphysema and only poorly and indirectly to bronchial airways obstructionin other words, that a measurement of diaphragmatic excursus may well be a useful aid in dis- 


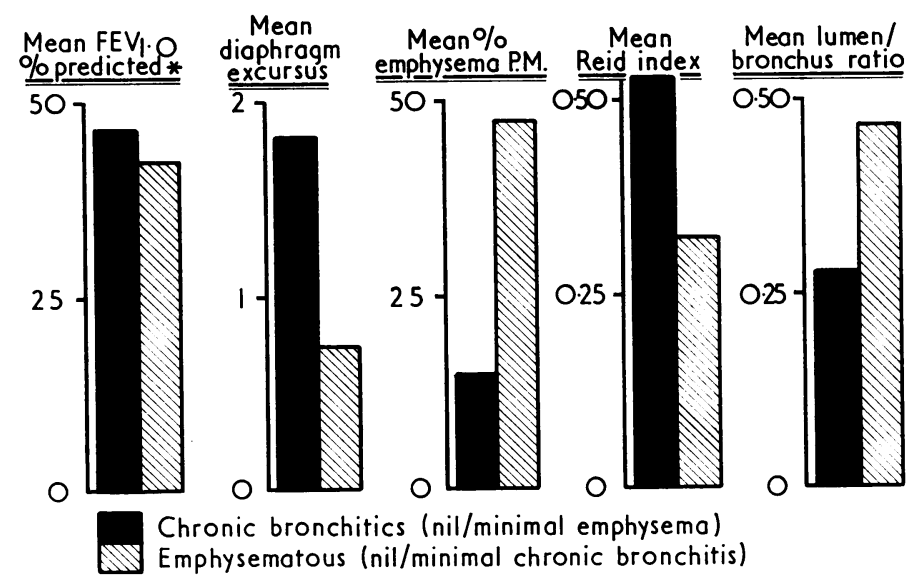

FIG. 2. Effect of emphysematous and bronchitic types of obstruction on $F E V_{1} *$ and diaphragmatic excursus. Numbers of subjects: emphysematous, 8 ; bronchitic, 10.

* Prediction formula of Ferris, Anderson and Zickmantel (1965).

criminating between the bronchial and emphysematous components in obstructive disease.

This possibility was looked at further in this series by identifying the predominantly bronchitic subjects in the series, for this purpose those with a Reid index greater than $0 \cdot 40$, a mean crosssectional area ratio (bronchial lumen/total bronchus to cartilage) less than 0.36 , and postmortem emphysema $20 \%$ or less-and, on the other hand, predominantly emphysematous subjects-those with a Reid index less than $0 \cdot 40$, bronchial cross-sectional area ratio greater than 0.36 , postmortem emphysema $25 \%$ or more. The results in terms of recorded diaphragmatic excursus are shown in Fig. 2. The recorded clinical histories of these subjects in general fitted the respective clinical patterns of the bronchitic and emphysematous types of obstructive airways disease as reported by Burrows et al. (1966). The finding of a near normal (just under 2 in or $5 \mathrm{~cm}$ ) mean range of diaphragm movement in the predominantly bronchitic members of the series shows clearly that it is the emphysematous component alone that determines restriction of movement.

DIAPHRAGMATIC MOVEMENT AND PNEUMOCONIOSIS The possibility that pneumoconiosis per se might be influencing the diaphragmatic excursus was examined by plotting the measured excursus against the quantified emphysema separately in groups with pathologically determined nil, sparse nodular, profuse nodular, and complicated (PMF) pneumoconiosis. The results are shown in Table II.

Further statistical testing showed that there was no significant shift between the regression lines representing the nil pneumoconiosis group and the group which included all the pneumoconiotic sub-

T A B L E I I

\begin{tabular}{l|c|c|c}
\hline & $\begin{array}{c}\text { Correlation } \\
\text { Coefficient }\end{array}$ & SE & $\begin{array}{c}\text { No. of } \\
\text { Subjects }\end{array}$ \\
\hline $\begin{array}{l}\text { Nil pneumoconiosis } \\
\begin{array}{c}\text { Sparse pneumoconiotic } \\
\text { nodules }\end{array}\end{array}$ & -0.86 & 0.07 & 14 \\
$\begin{array}{l}\text { Profuse pneumoconiotic } \\
\text { nodules }\end{array}$ & -0.76 & 0.08 & 25 \\
$\begin{array}{c}\text { Complicated (PMF) } \\
\text { pneumoconiosis }\end{array}$ & -0.89 & 0.06 & 10 \\
$\begin{array}{c}\text { Profuse nodules and/or } \\
\text { PMF }\end{array}$ & -0.85 & 0.13 & 8 \\
All pneumoconiotic subjects & -0.81 & 0.07 & 18 \\
\hline
\end{tabular}

jects, nor was there any difference between the of above two groups and the group which included $N$ only those subjects with profuse nodules and/or $\underset{\mathrm{N}}{\mathrm{N}}$ PMF pneumoconiosis. Further, when pneumo- $\sigma$ coniosis (using the categories sparse nodular, profuse nodular, and PMF) was plotted against the diaphragm excursus the correlation coefficient $\stackrel{\Phi}{+}$ was $0 \cdot 181$, SE 0.146 $(n=43)$.

Thus our findings do not support the pos- $\frac{0}{\circ}$ sibility that coal workers' pneumoconiotic fibrosis $\stackrel{\mathbb{D}}{\square}$ per se, as distinct from any accompanying $\stackrel{\mathbb{Q}}{\mathbb{Q}}$ emphysema, can reduce the range of movement of $\frac{\sigma}{\sigma}$ the diaphragm. 
DISCUSSION

The material presented shows that, at least in coal miners, not only is the diaphragmatic excursus reduced in emphysema but also that there is good linear correlation between it and the degree of emphysema present. In the presence of adequate prima facie evidence of emphysema, for example, the radiological signs mentioned earlier together with breathlessness and such other clinical, electrocardiographic, and physiological information as may be available, the range of movement observed fluoroscopically may be used as an aid to the assessment of its severity.

Whereas the numbers are small in the nil pneumoconiotic group, nevertheless the similarity of the regression lines with and without pneumoconiosis suggests to us that our findings apply to all types of generalized emphysema, not just that associated with coal dust deposits. Further, the previously quoted work of Simon and others supports the view that any or all types of emphysema may diminish the diaphragmatic excursus.

In our experience, respiratory incapacity in coal miners results commonly in practice from a mixture of pneumoconiosis, chronic bronchial airways obstruction, and emphysema in varying proportions. Impairment of diaphragmatic movement is used to help evaluate the emphysema component and is of no value in assessing the chronic bronchitic airways component though it may be present in the asthmatic whose lungs are overinflated.

Our finding of an absence of correlation between reduction in diaphragmatic movement and extent of coal workers' pneumoconiosis is perhaps not unexpected. The collagen component in the lesions of this type of pneumoconiosis is quite small and only with very large massive fibrotic lesions is there any appreciable stiffening of the lungs generally. However, if, as the authors do, one accepts the existence of the Gough 'dust focal' type emphysema as an entity, some indirect correlation might have been expected. But because of the frequency of non-pneumoconiotic emphysema, a much larger series is needed to bring out the relationships between pneumoconiosis and emphysema (and emphysema-related criteria). In our full necropsy series of some 750 subjects, an increase in mean emphysema severity with severity of pneumoconiosis was noted, especially at the massive stages. Overall emphysema severity also increased with years of experience at coal face employment in the mines, age for age.
The diagnosis of severity of emphysema pathology by clinical or radiological methods, particularly in the presence of chronic obstructive bronchitis, pneumoconiosis or asthma, has in the past achieved only a fairly low order of precision. Severe emphysema is usually readily recognized though occasionally mimicked radiologically by lung overinflation without emphysema.

In the authors' experience, emphysema with less than $20 \%$ lung involvement at necropsy has been largely undetected before death; nevertheless, careful use of clinical, radiological, and electrocardiographic signs and the results of physiological tests will often give a hint of its presence down to the region of $10-20 \%$ lung involvement. While this degree of emphysema is not ordinarily incapacitating, it can affect performance for extremes of physical effort. Above $20 \%$, breathlessness and incapacity increase rapidly with the extent of emphysema.

One must be reasonably certain that there are no other concurrent conditions present which could restrict diaphragm movement. Commoner examples of these are massive diaphragmatic adhesions, diaphragmatic paralysis, large spaceoccupying thoracic or abdominal lesions or extensive collagenous pulmonary fibrosis, lung overinflation due to asthma, pronounced obesity, restriction of respiratory range by pain, and, probably in some cases, thoracic cage deformity.

The above prediction formula has, in our experience, helped to improve the assessment of chronic lung disease. It has obvious limitations, particularly regarding accurate quantitation of emphysema, as evidenced by the individual subject tolerance limits $( \pm 16.5 \%)$. However, it appears that the method could be useful as a guide to the clinician in the approximate quantitation of emphysema in office practice, and is useful in field work at a distance from a large metropolis, particularly since FIFE films may be used in lieu of fluoroscopic screening if the latter facility is not available. For a full detailed analysis of the respiratory disorders of coal miners and others the assistance of the respiratory physiologist, equipped with sophisticated testing methods and apparatus, is required.

Our thanks are due to the Joint Coal Board for permission to publish this paper and also to the late Professor John Read, Department of Medicine, University of Sydney, New South Wales, Australia, for valued criticism and advice. 


\section{REFERENCES}

Burrows, B., Fletcher, C. M., Heard, B. E., Jones, N. L., and Wootliff, J. S. (1966). The emphysematous and bronchial types of chronic airways obstruction. Lancet, 1, 830.

Ferris, B. G. (Jr.), Anderson, D. O., and Zickmantel, R. (1965). Prediction values for screening tests of pulmonary function. Amer. Rev. resp. Dis., 91, 252.

McKenzie, H. I., Glick, M., and Outhred, K. G. (1969). Chronic bronchitis in coal miners: ante-mortem/postmortem comparisons. Thorax, 24, 527.

Milne, E. N. C., and Bass, H. (1969). Relationship between specific dynamic pulmonary compliance and diaphragmatic excursion. Radiology, 92, 615.
Reid, L. (1960). Measurement of the bronchial mucous gland layer: a diagnostic yardstick in chronic bronchitis. Thorax, 15, 132.

—, and Millard, F. J. C. (1964). Correlation between radiological diagnosis and structural lung changes in emphysema. Clin. Radiol., 15, 307.

Simon, G. (1956). Principles of Chest X-Ray Diagnosis. Butterworth, London.

(1964). Radiology and emphysema. Clin. Radiol., 15, 293. 